\title{
MULTISCALE ANALYSIS OF WAVE PROPAGATION IN COMPOSITE MATERIALS
}

\author{
C. CATTANI
}

diFARMA, University of Salerno

Via Ponte Don Melillo - Invariante 11/C - 84084 Fisciano (SA), Italy

E-mail: ccattani@unisa.it

Received August 13, 2003; revised November 16, 2003

\begin{abstract}
The multiscale solution of the Klein-Gordon equations in the linear theory of (two-phase) materials with microstructure is defined by using a family of wavelets based on the harmonic wavelets. The connection coefficients are explicitly computed and characterized by a set of differential equations. Thus the propagation is considered as a superposition of wavelets at different scale of approximation, depending both on the physical parameters and on the connection coefficients of each scale. The coarse level concerns with the basic harmonic trend while the small details, arising at more refined levels, describe small oscillations around the harmonic zero-scale approximation.
\end{abstract}

Key words: Harmonic Wavelets, Connection Coefficients, Multiscale, Klein-Gordon Equations.

\section{INTRODUCTION}

The evolution of a localized initial profile in the linear theory of (two-phase) materials with microstructure $[9 ; 12]$ is investigated by using a family of wavelets based on the so-called harmonic wavelets $[2 ; 6 ; 10 ; 11]$. The propagation is studied by decomposing the wave solution of the hyperbolic system into fundamental wavelets: each one corresponding to a scale approximation. During the time evolution some non trivial secondary oscillations in the wave propagation appear through the composite materials (like in the nonlinear wave propagation [5]). Thus the wave propagation is investigated at each scale, by showing that "minor" details in the solution, which are neglectable at the initial time, and on the coarse level approximation, have a significant influence on the evolution, on a long (time) range and refined scales. The 
multiscale (or multiresolution) approach is a kind of approximation method that at each (scale) step increases the "resolution" of the solution, so that at each scale more new details are added to the solution. The main hypothesis on solid mixtures is that the microstructure of a multi-component material is described by using a continuous medium, whose particles simultaneously, at each geometric point of the domain, interact with each other. In particular, the material with the microstructure is described by the microstructural theory of the second order linear theory of two-phase mixture $[5 ; 9 ; 12]$. The two interacting materials permit finite deformations and displacement $u_{k}^{(\alpha)}$ not only infinitely small. As a strain tensor is taken the linear symmetric Cauchy-Green strain tensor, in the deformation gradient $u_{i, k} \equiv \frac{\partial u_{i}}{\partial x^{k}},(i, k, \ldots=1,2,3)$,

$$
\varepsilon_{i k}^{(\alpha)}=\frac{1}{2}\left(u_{i, k}^{(\alpha)}+u_{i, k}^{(\alpha)}\right), \quad(\alpha=1,2)
$$

and for the stress, the asymmetric Piola-Kirchoff stress tensor $t_{i k}=\frac{\partial W}{\partial u_{k, i}}$, where the quadratic potential is given by [12]

$$
\begin{aligned}
W\left(\varepsilon_{i k}^{(\alpha)}\right)=\frac{\lambda_{\alpha}}{2}\left(\varepsilon_{m m}^{(\alpha)}\right)^{2} & +\mu_{\alpha}\left(\varepsilon_{i k}^{(\alpha)}\right)^{2}+2 \mu_{3}\left(\varepsilon_{i k}^{(\alpha)} \varepsilon_{i k}^{(\delta)}\right) \\
& +\lambda_{3}\left(\varepsilon_{m m}^{(\alpha)} \varepsilon_{m m}^{(\delta)}\right)+b\left(u_{k}^{(\alpha)}-u_{k}^{(\delta)}\right)^{2}
\end{aligned}
$$

here $\lambda, \mu$ are the Lamé elastic constants, $\alpha=1,2$ and $\delta=3-\alpha$. Numbers 1 and 2 refer to the material 1 and 2 respectively, of the two phase composite material, while number 3 corresponds to their product.

The interaction model is taken in a such a way that the basic shear force interaction for solid mixtures is the outcome of the relative motions of phases. The representative volume contains the particle-granules of both phases with different mechanical properties, and each separate phase is characterized by its physical parameters. The interaction between phases is linear and reflects the interaction between mechanical fields of both phases of the mixture.

Under the above hypotheses and assuming that the plane wave runs in the direction of the $x$-axis, so that there are only two independent variables: $x$ and the time $t$, the basic equations, for the (composite) medium in absence of external forces, are [12]:

$$
\rho_{\alpha} \frac{\partial^{2} u^{(\alpha)}}{\partial t^{2}}-a_{\alpha} \frac{\partial^{2} u^{(\alpha)}}{\partial x^{2}}-a_{3} \frac{\partial^{2} u^{(\delta)}}{\partial x^{2}}-b\left(u^{(\alpha)}-u^{(\delta)}\right)=0,
$$

where $\rho_{\alpha}$ is the partial density of the two-phase mixture, $u^{(\alpha)}$ is the partial displacement. Constants $a_{\alpha}, a_{3}, b$ are physical constants, that, in case of longitudinal (plane wave) propagation, are related to Lamé constants by the definitions [12]

$$
a_{\alpha} \equiv \lambda_{\alpha}+2 \mu_{\alpha}, \quad a_{3} \equiv \lambda_{3}+2 \mu_{3} .
$$


The multiscale solution of (1.1) will be expressed with respect to a wavelet basis, defined by a suitable modification of the harmonic wavelets [11]. Harmonic wavelets are finitely defined orthogonal basis, infinitely differentiable functions, band-limited in the Fourier domain. They are complex wavelets that seems to be very suitable for studying oscillations processes $[2 ; 6 ; 10]$.

The solution of (1.1) is searched as a wavelet series by fixing a finite upper limit $N<\infty$ (the scale approximation), in the series expansion. The (wavelet) coefficients of the series are determined as solution of suitable ordinary differential equations. The construction of these equations follows from the explicit computation of the connection coefficients. Due to both the localization and compression properties of wavelets, the wavelet coefficients play a fundamental role in the analysis of the problem. They can be considered as the essential parameters characterizing the phenomenon at different scales of approximation $[2 ; 3 ; 4]$. In wave propagation, very often, the approximate solution is expressed in terms of functions which are significant only at a given resolution, and, some time, also the exact solution (like e.g. the D'Alembert solution of the wave equation) shows two fundamental characteristic features of wavelets: the dilation (multiscale) and the translation properties. We will see that the wavelet solution of the Klein-Gordon equations at the level of resolution $N=0$ differs from that one of higher resolution $N=1$ for the existence of small amplitude waves. However, even if the details are neglectable at the initial time, after a sufficiently long time range they have significant values and give rise to subharmonic resonance as it happens in the nonlinear waves propagation [5].

\section{HARMONIC WAVELETS}

Let us consider, as wavelet basis, the complex valued functions $[2 ; 6]$

$$
\psi_{k}^{n}(x) \equiv \begin{cases}2^{-n / 2} \sum_{s=2^{n}}^{2^{n+1}-1} e^{-2 \pi i s\left(x-k / 2^{n}\right)}, & x \in[0,1], \\ 0, & \text { elsewhere }\end{cases}
$$

with $n, k \in \mathbb{N} \cup 0$. The functions $2^{-n / 2} \sum_{s=2^{n}}^{2^{n+1}-1} e^{-2 \pi i s\left(x-k / 2^{n}\right)}$ are the periodic harmonic wavelets, defined in [10] as a suitable generalization [7] of the harmonic wavelets [11]

$$
\psi(x) \equiv \frac{e^{4 \pi i x}-e^{2 \pi i x}}{2 \pi i x} .
$$

Functions (2.2), might be roughly considered as members of the Gaussian based wavelet family or better in the DOG (Difference of Gaussians) wavelets family [1]. Comparing with the Morlet wavelets (see e.g. [1; 7]),

$$
\psi_{k}^{n}(x) \equiv 2^{-n / 2} \pi^{-1 / 4} e^{2 \pi i f_{0}\left(x-k / 2^{n}\right)} e^{-x^{2} / 2}, \quad f_{0} \gg 0,
$$



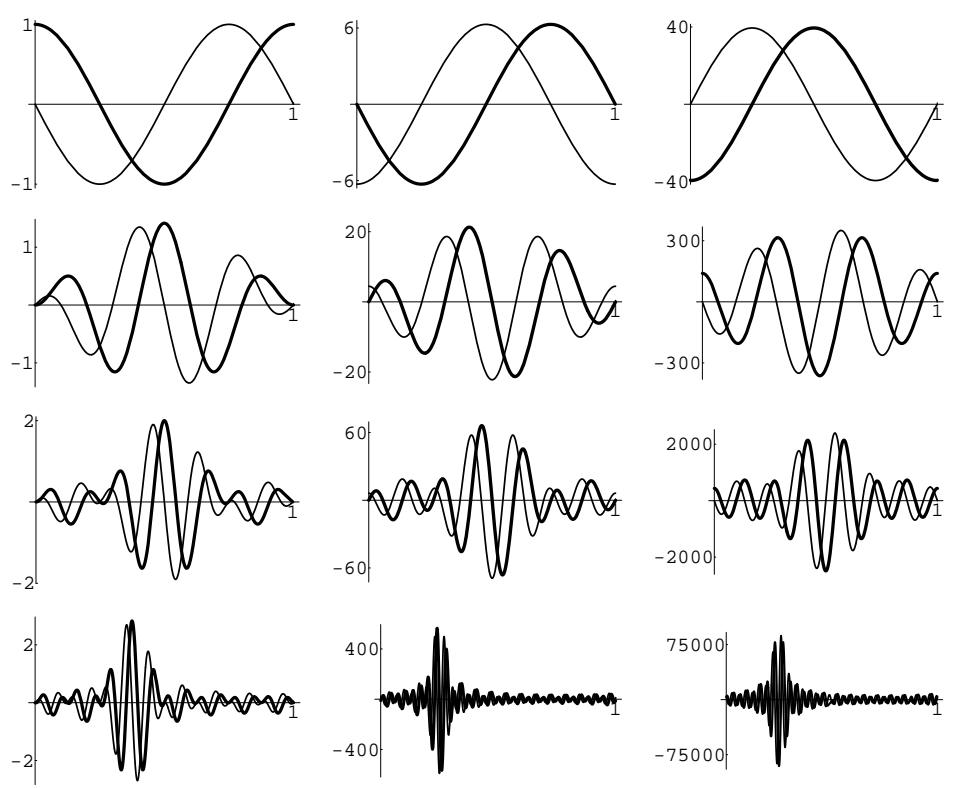

Figure 1. Real (thick line) and imaginary (thin line) part of the periodic harmonic wavelets $\psi_{0}^{0}(x), \psi_{1}^{1}(x), \psi_{2}^{2}(x) \psi_{4}^{4}(x)$ (first column, from top to bottom) and their corresponding first derivative (second column) and second derivatives (third column), in the interval $[0,1]$.

the Fourier transform of each harmonic wavelet (2.2) is a band limited function (box function in the Fourier domain) while the Fourier transform of the Morlet wavelets are shifted Gaussian. Harmonic wavelets are closely related, in their definition, to the Shannon wavelets (see e.g. [8]), or sinc-function based wavelets, which are band limited (box functions in the Fourier domain) too, but they are only real functions in the $x$-domain.

Functions $(2.1)_{1}$ are differentiable functions so that we assume

$$
\left\{\begin{array}{l}
\frac{d \psi_{k}^{n}(x)}{d x}=-2^{-n / 2+1} \sum_{s=2^{n}}^{2^{n+1}-1} i \pi s e^{-2 \pi i s\left(x-k / 2^{n}\right)}, \\
\frac{d^{2} \psi_{k}^{n}(x)}{d x^{2}}=-2^{-n / 2+2} \sum_{s=2^{n}}^{2^{n+1}-1}(\pi s)^{2} e^{-2 \pi i s\left(x-k / 2^{n}\right)},
\end{array}\right.
$$

for the first and second derivatives, respectively (see, Fig. 1). 


\subsection{CONNECTION COEFFICIENTS}

Let $f(x), g(x)$ be functions with compact support on the unit interval $[0,1]$; we assume as scalar product: $\langle f, g\rangle \equiv \int_{0}^{1} f(x) \overline{g(x)} d x$, where the bar stands for the complex conjugate. Wavelets (2.1) are orthogonal functions in the sense that $\left\langle\psi_{k}^{n}, \psi_{h}^{m}\right\rangle=\delta^{n m}$. From the definition (2.1) and the equations (2.3), there easily follow the linear connection coefficients $([2 ; 6 ; 10])$,

$$
\begin{aligned}
\gamma_{k h}^{n m} & \equiv\left\langle\frac{d}{d x} \psi_{k}^{n}(x), \psi_{h}^{m}(x)\right\rangle=-\left\langle\psi_{k}^{n}(x) \frac{d}{d x} \psi_{h}^{m}(x)\right\rangle \\
& =-2^{-(n+m) / 2+1} \sum_{s=2^{n}}^{2^{n+1}-1} \sum_{r=2^{m}}^{2^{m+1}-1} i \pi s \int_{0}^{1} e^{2 \pi i\left[(r-s) x-\left(h / 2^{m}-k / 2^{n}\right)\right]} d x
\end{aligned}
$$

and since $\int_{0}^{1} e^{2 \pi i m x} d x=\delta_{m 0}, m \in \mathbb{Z}$, the unvanishing components of the connection coefficients are only those for which $n=m$. With a simple computation we obtain [2],

$$
\gamma_{k h}^{n m}=\left(-2^{1-n} \pi i \sum_{s, r=2^{n}}^{2^{n+1}-1} s e^{-2^{1-n} \pi i(h-k)} \delta_{r s}\right) \delta^{n m}
$$

where $\delta_{r s}$ is the Kronecker symbol. In particular, taking into account that $k=0, \ldots 2^{n}-1, h=0, \ldots 2^{m}-1$ we have, at the lower scales $n=m=0,1,2$ :

$$
\begin{gathered}
\gamma_{00}^{00}=-2 \pi i, \quad \gamma_{k h}^{11}=5 \pi\left(\begin{array}{rrr}
-i & i \\
i & -i
\end{array}\right), \\
\gamma_{k h}^{22}=11 \pi\left(\begin{array}{rrrr}
-i & 1 & i & -1 \\
-1 & -i & 1 & i \\
i & -1 & -i & 1 \\
1 & i & -1 & -i
\end{array}\right) .
\end{gathered}
$$

Analogously, we have, for the connection coefficients of the second derivative,

$$
\begin{aligned}
\Gamma_{k h}^{n m} & \equiv\left\langle\frac{d^{2}}{d x^{2}} \psi_{k}^{n}(x), \psi_{h}^{m}(x)\right\rangle \\
\Gamma_{k h}^{n m} & =\left(-2^{(n+m) / 2+2} \pi^{2} \sum_{s, r=2^{n}}^{2^{n+1}-1} s^{2} e^{-2^{1-n} \pi i(h-k)} \delta_{r s}\right) \delta^{n m},
\end{aligned}
$$


so that, at the lower scales $n=m=0,1,2$, it is:

$$
\begin{aligned}
& \Gamma_{00}^{00}=-4 \pi^{2}, \quad \Gamma_{k h}^{11}=26 \pi^{2}\left(\begin{array}{rrr}
-1 & 1 \\
1 & -1
\end{array}\right), \\
& \Gamma_{k h}^{22}=126 \pi^{2}\left(\begin{array}{rrrr}
-1 & -i & 1 & i \\
i & -1 & -i & 1 \\
1 & i & -1 & -i \\
-i & 1 & i & -1
\end{array}\right)
\end{aligned}
$$

\subsection{Harmonic differential equations}

The wavelets (2.1), can be obtained also as solutions of a class of differential equations, as follows. The connection coefficients (2.4)-(2.6) are not independent due to the following relations

$$
\Gamma_{00}^{00}=\left(\gamma_{00}^{00}\right)^{2}, \Gamma_{k h}^{11}=\frac{13}{25}\left(\gamma_{k h}^{11}\right)^{2}, \Gamma_{k h}^{22}=\frac{63}{242}\left(\gamma_{k h}^{22}\right)^{2}, \Gamma_{k h}^{33}=\frac{275}{2116}\left(\gamma_{k h}^{33}\right)^{2}, \ldots
$$

where $\left(\gamma_{k h}^{N N}\right)^{2} \equiv \sum_{m=0}^{2^{N}-1} \gamma_{k m}^{N N} \gamma_{m h}^{N N}$ is the matrix product. In general, it can be seen that a recursive formula

$$
\Gamma_{k h}^{N N}=c_{N}\left(\gamma_{k h}^{N N}\right)^{2}, N \geq 0, k, h=0, \ldots 2^{N}-1
$$

relates the two sets of connection coefficients, where the sequence of constants $c_{N}$ is explicitly defined by the recursive forward formulas

$$
\left\{\begin{array}{l}
b_{0}=2, d_{0}=2 \\
b_{N}=4 b_{N-1}+d_{N}, d_{N}=2 d_{N-1}+1, \quad N \geq 1 \\
c_{N} \equiv \frac{b_{N}}{2^{N-1} d_{N}^{2}} .
\end{array}\right.
$$

Thus we have the following

Theorem 2.1. The wavelets (2.1) are solution of the Cauchy problem

$$
\left\{\begin{array}{l}
\frac{d^{2}}{d x^{2}} \psi_{k}^{N}(x)=c_{N} \sum_{m=0}^{2^{N}-1} \gamma_{k m}^{N N} \frac{d}{d x} \psi_{m}^{N}(x)(x), \quad k=0, \ldots 2^{N}-1 \\
\psi_{k}^{N}\left(k / 2^{N}\right)=2^{N / 2} \\
\left.\frac{d}{d x} \psi_{k}^{N}(x)\right|_{x=k / 2^{N}}=-2^{-N / 2+1} \sum_{s=2^{N}}^{2^{N+1}-1} i \pi s
\end{array}\right.
$$


where $c_{N}$ and $\gamma_{k m}^{N N}$ are given by (2.9) and (2.4) respectively.

Proof. From equation (2.8), taking into account the definitions (2.4)-(2.6), one obtains for $h, k=0, \ldots 2^{N}-1$

$$
\left\langle\frac{d^{2}}{d x^{2}} \psi_{k}^{N}(x), \psi_{h}^{N}(x)\right\rangle=c_{N} \sum_{m=0}^{2^{N}-1}\left\langle\frac{d}{d x} \psi_{k}^{N}(x), \psi_{m}^{N}(x)\right\rangle\left\langle\frac{d}{d x} \psi_{m}^{N}(x), \psi_{h}^{N}(x)\right\rangle,
$$

from where (2.10) easily follows.

For instance when $N=0$, equation (2.10), with $c_{0}$ according to (2.9), gives

$$
\frac{d^{2}}{d x^{2}} \psi_{0}^{0}(x)=-2 \pi i \frac{d}{d x} \psi_{0}^{0}(x)
$$

This equation is solved by the function

$$
\psi_{0}^{0}(x)=C_{1}(i / 2 \pi) e^{-2 i \pi x}+C_{2},
$$

where the integration constants $C_{1}, C_{2}$, according to the initial conditions are $C_{1}=-2 i \pi, C_{2}=0$. So the solution coincides with (2.1), where it is assumed that $n=0, k=0$.

\section{HARMONIC WAVELET SOLUTIONS}

We assume as solution of the equations $(1)$, in the interval $[0,1]$, the following functions, depending on the (scale) level of approximation $N \in \mathbb{N} \cup\{0\}$,

$$
\left\{\begin{array}{l}
u^{1}(x, t)=\sum_{n=0}^{2^{N}-1} \sum_{k=0}^{2^{n}-1} \beta_{k}^{n}(t) \psi_{k}^{n}(x)+\widehat{\beta}_{k}^{n}(t) \overline{\psi_{k}^{n}}(x), \\
u^{2}(x, t)=\sum_{n=0}^{2^{N}-1} \sum_{k=0}^{2^{n}-1} \eta_{k}^{n}(t) \psi_{k}^{n}(x)+\widehat{\eta}_{k}^{n}(t) \overline{\psi_{k}^{n}}(x)
\end{array}\right.
$$

with $\psi_{k}^{n}(x)$ given by (2.1). Taking into account the orthogonality property of the harmonic wavelets and their conjugate functions, system (1.1), with (3.1), becomes

$$
\begin{array}{r}
\rho_{1} \sum_{k, n}^{N}\left(\frac{d^{2}}{d t^{2}} \beta_{k}^{n}(t)\right) \psi_{k}^{n}(x)-a_{1} \sum_{k, n}^{N} \beta_{k}^{n}(t)\left(\frac{d^{2}}{d x^{2}} \psi_{k}^{n}(x)\right)-a_{3} \sum_{k, n}^{N} \eta_{k}^{n}(t) \\
\times\left(\frac{d^{2}}{d x^{2}} \psi_{k}^{n}(x)\right)-b\left(\sum_{k, n}^{N} \beta_{k}^{n}(t) \psi_{k}^{n}(x)-\sum_{k, n}^{N} \eta_{k}^{n}(t) \psi_{k}^{n}(x)\right)=0
\end{array}
$$




$$
\begin{aligned}
\rho_{2} \sum_{k, n}^{N} & \left(\frac{d^{2}}{d t^{2}} \eta_{k}^{n}(t)\right) \psi_{k}^{n}(x)-a_{2} \sum_{k, n}^{N} \eta_{k}^{n}(t)\left(\frac{d^{2}}{d x^{2}} \psi_{k}^{n}(x)\right)-a_{3} \sum_{k, n}^{N} \beta_{k}^{n}(t) \\
& \times\left(\frac{d^{2}}{d x^{2}} \psi_{k}^{n}(x)\right)-b\left(\sum_{k, n}^{N} \eta_{k}^{n}(t) \psi_{k}^{n}(x)-\sum_{k, n}^{N} \beta_{k}^{n}(t) \psi_{k}^{n}(x)\right)=0
\end{aligned}
$$

where, for short, we denote $\sum_{k, n}^{N} \equiv \sum_{n=0}^{2^{N}-1} \sum_{k=0}^{2^{n}-1}$. A similar system must be written for the other unknown coefficient functions $\widehat{\beta}_{k}^{n}(t), \widehat{\eta}_{k}^{n}(t)$ with respect to the conjugate wavelet basis $\overline{\psi_{k}^{n}}(x)$.

By a scalar product with $\psi_{k}^{n}(t)$, taking into account the connection coefficients (2.6), and the orthogonality conditions, there follows

$$
\left\{\begin{array}{c}
\rho_{1}\left(\frac{d^{2}}{d t^{2}} \beta_{h}^{m}(t)\right)-a_{1} \sum_{k, n}^{N} \beta_{k}^{n}(t) \Gamma_{k h}^{n m}-a_{3} \sum_{k, n}^{N} \eta_{k}^{n}(t) \Gamma_{k h}^{n m} \\
-b\left(\beta_{h}^{m}(t)-\eta_{h}^{m}(t)\right)=0 \\
\rho_{2}\left(\frac{d^{2}}{d t^{2}} \eta_{h}^{m}(t)\right)-a_{2} \sum_{k, n}^{N} \eta_{k}^{n}(t) \Gamma_{k h}^{n m}-a_{3} \sum_{k, n}^{N} \beta_{k}^{n}(t) \Gamma_{k h}^{n m} \\
-b\left(\eta_{h}^{m}(t)-\beta_{h}^{m}(t)\right)=0
\end{array}\right.
$$

with $h=0, \ldots, 2^{m}-1, m=0, \ldots, 2^{N}-1$. Thus we have a linear ordinary differential system for the unknown functions $\beta_{h}^{m}(t), \eta_{h}^{m}(t)$, and the same system for the cap functions $\widehat{\beta}_{k}^{n}(t), \eta_{k}^{n}(t)$, whose general solution depends on the initial conditions as well on the geometrical constant coefficients $\Gamma_{k h}^{n m}$ and the physical parameters $\rho_{1}, \rho_{2}, a_{1}, a_{2}, a_{3}, b$. In particular, assuming $\beta_{h}^{m}(t)=$ $\widehat{\beta}_{h}^{m}(t), \eta_{h}^{m}(t)=\widehat{\eta}_{h}^{m}(t)$, we will focus only on the equations for $\beta_{h}^{m}(t), \eta_{h}^{m}(t)$ and the wavelet solution (3.1), is reduced to the functions

$$
\begin{aligned}
& u^{1}(x, t)=\sum_{n=0}^{2^{N}-1} \sum_{k=0}^{2^{n}-1} \beta_{k}^{n}(t)\left[2^{-n / 2} \sum_{s=2^{n}}^{2^{n+1}-1}\left(e^{-2 i \pi\left(x-k / 2^{n}\right)}+e^{2 i \pi\left(x-k / 2^{n}\right)}\right)\right], \\
& u^{2}(x, t)=\sum_{n=0}^{2^{N}-1} \sum_{k=0}^{2^{n}-1} \eta_{k}^{n}(t)\left[2^{-n / 2} \sum_{s=2^{n}}^{2^{n+1}-1}\left(e^{-2 i \pi\left(x-k / 2^{n}\right)}+e^{2 i \pi\left(x-k / 2^{n}\right)}\right)\right],
\end{aligned}
$$

or, in trigonometric form,

$$
u^{1}(x, t)=\sum_{n=0}^{2^{N}-1} \sum_{k=0}^{2^{n}-1} \beta_{k}^{n}(t)\left[2^{1-n / 2} \sum_{s=2^{n}}^{2^{n+1}-1} \cos 2 \pi s\left(x-k / 2^{n}\right)\right],
$$




$$
u^{2}(x, t)=\sum_{n=0}^{2^{N}-1} \sum_{k=0}^{2^{n}-1} \eta_{k}^{n}(t)\left[2^{1-n / 2} \sum_{s=2^{n}}^{2^{n+1}-1} \cos 2 \pi s\left(x-k / 2^{n}\right)\right] .
$$

\section{WAVELET SOLUTION AT THE SCALE $N=0$}

At the lowest scale, system (3.2) gives

$$
\left\{\begin{array}{l}
\rho_{1}\left(\frac{d^{2}}{d t^{2}} \beta_{0}^{0}(t)\right)+4 \pi^{2} a_{1} \beta_{0}^{0}(t)+4 \pi^{2} a_{3} \eta_{0}^{0}(t)-b\left(\beta_{0}^{0}(t)-\eta_{0}^{0}(t)\right)=0, \\
\rho_{2}\left(\frac{d^{2}}{d t^{2}} \eta_{0}^{0}(t)\right)+4 \pi^{2} a_{2} \eta_{0}^{0}(t)+4 \pi^{2} a_{3} \beta_{0}^{0}(t)-b\left(\eta_{0}^{0}(t)-\beta_{0}^{0}(t)\right)=0 .
\end{array}\right.
$$

We will explicitly give two solutions of this system, unstable and stable respectively, the stability depends on the physical parameters.

\subsection{Unstable solution}

Let us take, as initial conditions, the profiles

$$
\left\{\begin{array}{l}
u^{1}(x, 0)=\beta_{0}^{0}(0)\left[\psi_{0}^{0}(x)+\overline{\psi_{0}^{0}}(x)\right]=2 \cos 2 \pi x \\
u^{2}(x, 0)=\eta_{0}^{0}(0)\left[\psi_{0}^{0}(x)+\overline{\psi_{0}^{0}}(x)\right]=4 \cos 2 \pi x \\
\left.\frac{\partial u^{1}}{\partial t}\right|_{t=0}=\left.\frac{\partial u^{2}}{\partial t}\right|_{t=0}=0
\end{array}\right.
$$

so that

$$
\beta_{0}^{0}(0)=1,\left.\frac{d \beta_{0}^{0}(t)}{d t}\right|_{t=0}=0, \eta_{0}^{0}(0)=2,\left.\frac{d \eta_{0}^{0}(t)}{d t}\right|_{t=0}=0 .
$$

Assuming for the physical parameters the following values

$$
\rho_{1}=1, \rho_{2}=2, a_{1}=1, a_{2}=2, a_{3}=3, b=2
$$

(so that $a_{1} a_{2}<\left(a_{3}\right)^{2}$ ), we obtain

$$
\begin{aligned}
& \beta_{0}^{0}(t)=1.91 \cos 11.09 t-0.91 \cosh 6.86 t, \\
& \eta_{0}^{0}(t)=1.35 \cos 11.09 t+0.65 \cosh 6.86 t,
\end{aligned}
$$

from where the solution is given by

$$
\left\{\begin{array}{l}
u^{1}(x, t)=(1.91 \cos 11.09 t-0.91 \cosh 6.86 t) \cos 2 \pi x \\
u^{2}(x, 0)=(1.35 \cos 11.09 t+0.65 \cosh 6.86 t) \cos 2 \pi x
\end{array}\right.
$$


The evolution of the initial profiles is such that the amplitude of the wave resulting from their combination $u(x, t)=u^{1}(x, t)+u^{2}(x, t)$, is rapidly growing (see Fig. 2). However, there are some nodes, where $u(x, t)=0$, that can be seen both from the projection into the plane $t=0$ and from that one into the plane $x=0$ (see Fig. 3).

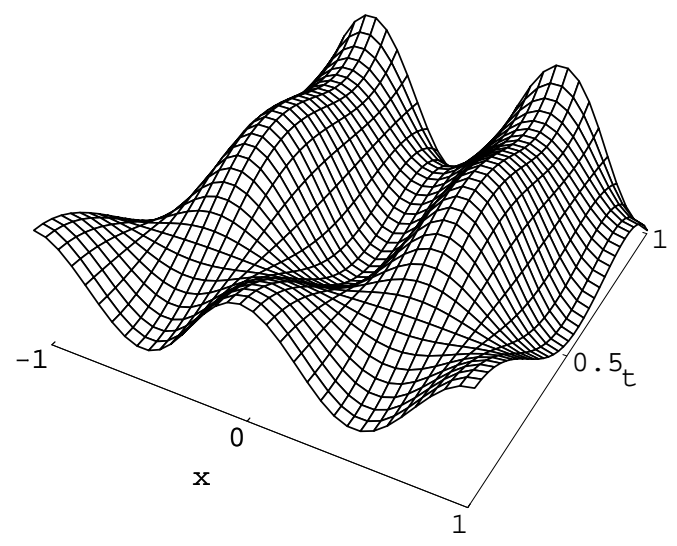

Figure 2. Unbounded solution at the scale $N=0$.
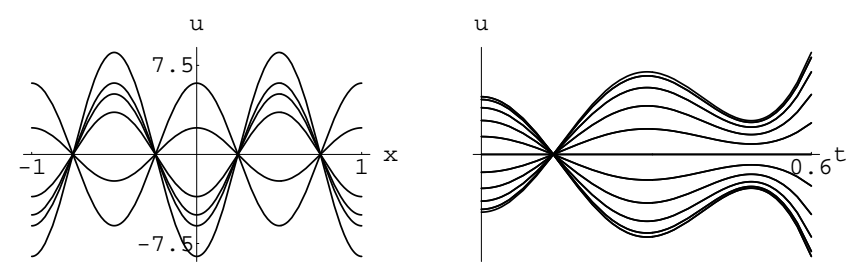

Figure 3. Projection of the unbounded solution at the scale $N=0$.

\subsection{Stable solution}

With the same initial conditions (4.1), we take for the physical parameters

$$
\rho_{1}=1, \quad \rho_{2}=2, \quad a_{1}=1, \quad a_{2}=2, a_{3}=1 / 3, \quad b=10
$$

so that $a_{1} a_{2}>\left(a_{3}\right)^{2}$ and $b<\frac{4 \pi^{2}\left(a_{1} a_{2}-\left(a_{3}\right)^{2}\right)}{a_{1}+a_{2}+2 a_{3}} \cong 20.3$. Thus we obtain

$$
\begin{aligned}
& \beta_{0}^{0}(t)=-0.69 \cos 4.75 t+1.69 \cos 7.02 t \\
& \eta_{0}^{0}(t)=0.67 \cos 4.75 t+1.32 \cos 7.02 t
\end{aligned}
$$


and then the solution is given by

$$
\left\{\begin{array}{l}
u^{1}(x, t)=(-0.69 \cos 4.75 t+1.69 \cos 7.02 t) \cos 2 \pi x \\
u^{2}(x, 0)=(0.67 \cos 4.75 t+1.32 \cos 7.02 t) \cos 2 \pi x
\end{array}\right.
$$

The evolution of the initial profiles is such that the amplitude of the wave resulting from their combination $u(x, t)=u^{1}(x, t)+u^{2}(x, t)$, is bounded (see Fig. 4, 5).

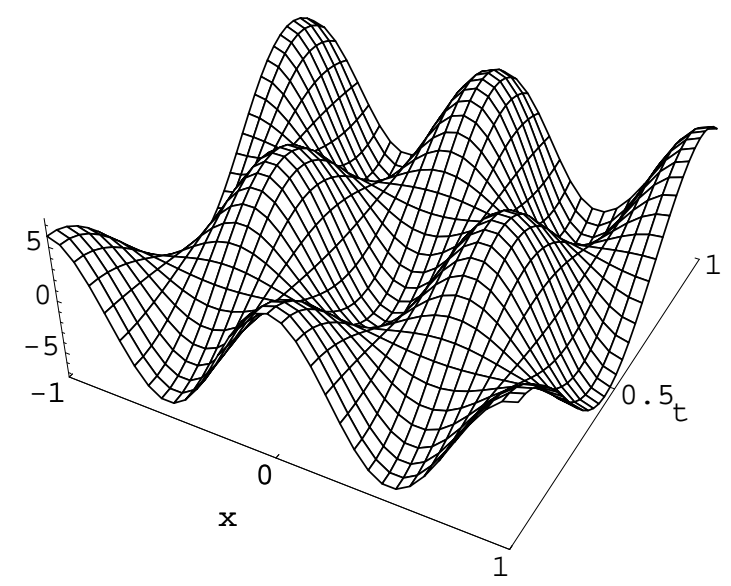

Figure 4. Bounded solution at the scale $N=0$.
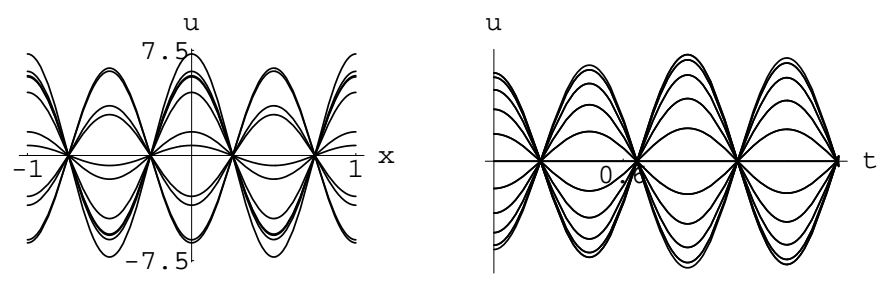

Figure 5. Projection of the bounded solution at the scale $N=0$.

\section{WAVELET SOLUTION AT THE SCALE $N=1$}

At the scale $N=1$, system $(3.2)$ gives $(m, h=0,1,2)$

$$
\begin{array}{r}
\rho_{1}\left(\frac{d^{2}}{d t^{2}} \beta_{h}^{m}(t)\right)-a_{1}\left(\beta_{0}^{0}(t) \Gamma_{0 h}^{0 m}+\beta_{0}^{1}(t) \Gamma_{0 h}^{1 m}+\beta_{1}^{1}(t) \Gamma_{1 h}^{1 m}\right)-a_{3}\left(\eta_{0}^{0}(t) \Gamma_{0 h}^{0 m}\right. \\
\left.+\eta_{0}^{1}(t) \Gamma_{0 h}^{1 m}+\eta_{1}^{1}(t) \Gamma_{1 h}^{1 m}\right)-b\left(\beta_{h}^{m}(t)-\eta_{h}^{m}(t)\right)=0
\end{array}
$$




$$
\begin{aligned}
& \rho_{2}\left(\frac{d^{2}}{d t^{2}} \eta_{h}^{m}(t)\right)-a_{2}(\left.\eta_{0}^{0}(t) \Gamma_{0 h}^{0 m}+\eta_{0}^{1}(t) \Gamma_{0 h}^{1 m}+\eta_{1}^{1}(t) \Gamma_{1 h}^{1 m}\right)-a_{3}\left(\beta_{0}^{0}(t) \Gamma_{0 h}^{0 m}\right. \\
&\left.+\beta_{0}^{1}(t) \Gamma_{0 h}^{1 m}+\beta_{1}^{1}(t) \Gamma_{1 h}^{1 m}\right)-b\left(\eta_{h}^{m}(t)-\beta_{h}^{m}(t)\right)=0 .
\end{aligned}
$$

So that, taking into account the expression of the connection coefficients (2.6)(2.7), there follows, for $m=h=0$, the same equations already solved in the case $N=0$, but in addition we have for $m=1$ and $h=0,1$ additional equations for the coefficients $\beta_{0}^{1}(t), \beta_{1}^{1}(t), \eta_{0}^{1}(t), \eta_{1}^{1}(t)$ :

$$
\begin{aligned}
\rho_{1}\left(\frac{d^{2}}{d t^{2}} \beta_{0}^{1}(t)\right)-a_{1}\left(\beta_{0}^{1}(t) \Gamma_{00}^{11}+\beta_{1}^{1}(t) \Gamma_{10}^{11}\right) & -a_{3}\left(\eta_{0}^{1}(t) \Gamma_{00}^{11}+\eta_{1}^{1}(t) \Gamma_{10}^{11}\right) \\
& -b\left(\beta_{0}^{1}(t)-\eta_{0}^{1}(t)\right)=0, \\
\rho_{1}\left(\frac{d^{2}}{d t^{2}} \beta_{1}^{1}(t)\right)-a_{1}\left(\beta_{0}^{1}(t) \Gamma_{01}^{11}+\beta_{1}^{1}(t) \Gamma_{11}^{11}\right) & -a_{3}\left(\eta_{0}^{1}(t) \Gamma_{01}^{11}+\eta_{1}^{1}(t) \Gamma_{11}^{11}\right) \\
& -b\left(\beta_{1}^{1}(t)-\eta_{1}^{1}(t)\right)=0, \\
\rho_{2}\left(\frac{d^{2}}{d t^{2}} \eta_{0}^{1}(t)\right)-a_{2}\left(\eta_{0}^{1}(t) \Gamma_{00}^{11}+\eta_{1}^{1}(t) \Gamma_{10}^{11}\right) & -a_{3}\left(\beta_{0}^{1}(t) \Gamma_{00}^{11}+\beta_{1}^{1}(t) \Gamma_{10}^{11}\right) \\
& -b\left(\eta_{0}^{1}(t)-\beta_{0}^{1}(t)\right)=0, \\
\rho_{2}\left(\frac{d^{2}}{d t^{2}} \eta_{1}^{1}(t)\right)-a_{2}\left(\eta_{0}^{1}(t) \Gamma_{01}^{11}+\eta_{1}^{1}(t) \Gamma_{11}^{11}\right) & -a_{3}\left(\beta_{0}^{1}(t) \Gamma_{01}^{11}+\beta_{1}^{1}(t) \Gamma_{11}^{11}\right) \\
& -b\left(\eta_{1}^{1}(t)-\beta_{1}^{1}(t)\right)=0,
\end{aligned}
$$

or, explicitly,

$$
\begin{gathered}
\rho_{1}\left(\frac{d^{2}}{d t^{2}} \beta_{0}^{1}(t)\right)-26 \pi^{2} a_{1}\left(-\beta_{0}^{1}(t)+\beta_{1}^{1}(t)\right)- \\
-b\left(\beta_{0}^{1}(t)-\eta_{0}^{1}(t)\right)=0, \\
\rho_{1}\left(\frac{d^{2}}{d t^{2}} \beta_{1}^{1}(t)\right)-26 \pi^{2} a_{1}\left(\beta_{0}^{1}(t)-\beta_{1}^{1}(t)\right)-26 \pi^{2} a_{3}\left(\eta_{0}^{1}(t)-\eta_{1}^{1}(t)\right) \\
-b\left(\beta_{1}^{1}(t)-\eta_{1}^{1}(t)\right)=0, \\
\rho_{2}\left(\frac{d^{2}}{d t^{2}} \eta_{0}^{1}(t)\right)-26 \pi^{2} a_{2}\left(-\eta_{0}^{1}(t)+\eta_{1}^{1}(t)\right)-26 \pi^{2} a_{3}\left(-\beta_{0}^{1}(t)+\beta_{1}^{1}(t)\right) \\
-b\left(\eta_{0}^{1}(t)-\beta_{0}^{1}(t)\right)=0, \\
\rho_{2}\left(\frac{d^{2}}{d t^{2}} \eta_{1}^{1}(t)\right)-26 \pi^{2} a_{2}\left(\eta_{0}^{1}(t)-\eta_{1}^{1}(t)\right)-26 \pi^{2} a_{3}\left(\beta_{0}^{1}(t)-\beta_{1}^{1}(t) \Gamma_{11}^{11}\right) \\
-b\left(\eta_{1}^{1}(t)-\beta_{1}^{1}(t)\right)=0 .
\end{gathered}
$$




\subsection{Stable solution}

Let us take, as initial conditions,

$$
\begin{aligned}
w^{1}(x, 0) & =\beta_{0}^{0}(0)\left[\psi_{0}^{0}(x)+\overline{\psi_{0}^{0}}(x)\right]+\beta_{1}^{1}(0)\left[\psi_{1}^{1}(x)+\overline{\psi_{1}^{1}}(x)\right] \\
& =2 \cos 2 \pi x+\frac{2^{1 / 2}}{100}[\cos 4 \pi(x-1 / 2)+\cos 6 \pi(x-1 / 2)], \\
w^{2}(x, 0) & =\eta_{0}^{0}(0)\left[\psi_{0}^{0}(x)+\overline{\psi_{0}^{0}}(x)\right]+\eta_{1}^{1}(0)\left[\psi_{1}^{1}(x)+\overline{\psi_{1}^{1}}(x)\right] \\
& =4 \cos 2 \pi x+\frac{2^{3 / 2}}{100}[\cos 4 \pi(x-1 / 2)+\cos 6 \pi(x-1 / 2)], \\
\left.\frac{\partial u^{1}}{\partial t}\right|_{t=0} & =\left.\frac{\partial u^{2}}{\partial t}\right|_{t=0}=0,
\end{aligned}
$$

so that

$$
\begin{aligned}
& \beta_{0}^{0}(0)=1, \beta_{0}^{1}(0)=0, \beta_{1}^{1}(0)=0.01, \\
& \left.\frac{d \beta_{0}^{0}(t)}{d t}\right|_{t=0}=0,\left.\frac{d \beta_{0}^{1}(t)}{d t}\right|_{t=0}=0,\left.\frac{d \beta_{1}^{1}(t)}{d t}\right|_{t=0}=0, \\
& \eta_{0}^{0}(0)=2, \eta_{0}^{1}(0)=0, \eta_{1}^{1}(0)=0.02, \\
& \left.\frac{d \eta_{0}^{0}(t)}{d t}\right|_{t=0}=0,\left.\frac{d \eta_{0}^{1}(t)}{d t}\right|_{t=0}=0,\left.\frac{d \eta_{1}^{1}(t)}{d t}\right|_{t=0}=0 .
\end{aligned}
$$

Assuming, as before,

$$
\rho_{1}=1, \rho_{2}=2, \quad a_{1}=1, a_{2}=2, a_{3}=1 / 3, \quad b=10,
$$

so that the 0 -scale solution is stable, we obtain the contribution of the details $\beta_{0}^{1}(t), \beta_{1}^{1}(t), \eta_{0}^{1}(t), \eta_{1}^{1}(t)$. As can be seen from Fig. 6, all the coefficients give very little (neglectable) contribution to the initial $(t<1)$ evolution in time, but their influence grows very rapidly when $(t>1)$. In fact, if we define

$$
\begin{aligned}
& v^{1}(x, t)=\beta_{0}^{1}(t)\left[\psi_{0}^{1}(x)+\overline{\psi_{0}^{1}}(x)\right]+\beta_{1}^{1}(t)\left[\psi_{1}^{1}(x)+\overline{\psi_{1}^{1}}(x)\right], \\
& v^{2}(x, t)=\eta_{0}^{1}(t)\left[\psi_{0}^{1}(x)+\overline{\psi_{0}^{1}}(x)\right]+\eta_{1}^{1}(t)\left[\psi_{1}^{1}(x)+\overline{\psi_{1}^{1}}(x)\right],
\end{aligned}
$$

the solution $w^{\alpha}(x, t),(\alpha=1,2)$ is the combination of the basic trend $u^{\alpha}(x, t)$ (of the level $N=0$ ) with the "details oscillations" $v^{\alpha}(x, t)$ at the level $N=1$,

$$
\begin{aligned}
& w^{1}(x, t)=u^{1}(x, t)+v^{1}(x, t), \\
& w^{2}(x, t)=u^{2}(x, t)+v^{2}(x, t),
\end{aligned}
$$



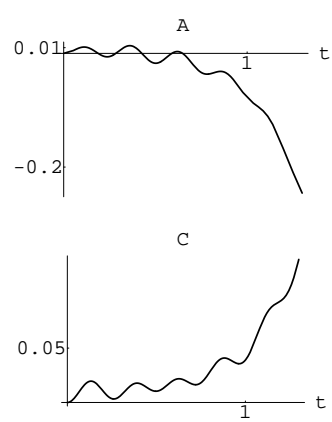
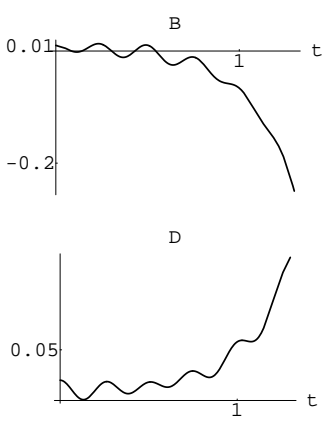

Figure 6. Wavelet coefficients at the level $N=1$. A: $\beta_{0}^{1}(t)$, $\mathrm{B}: \beta_{1}^{1}(t), \mathrm{C}: \eta_{0}^{1}(t), \mathrm{D}: \eta_{1}^{1}(t)$.
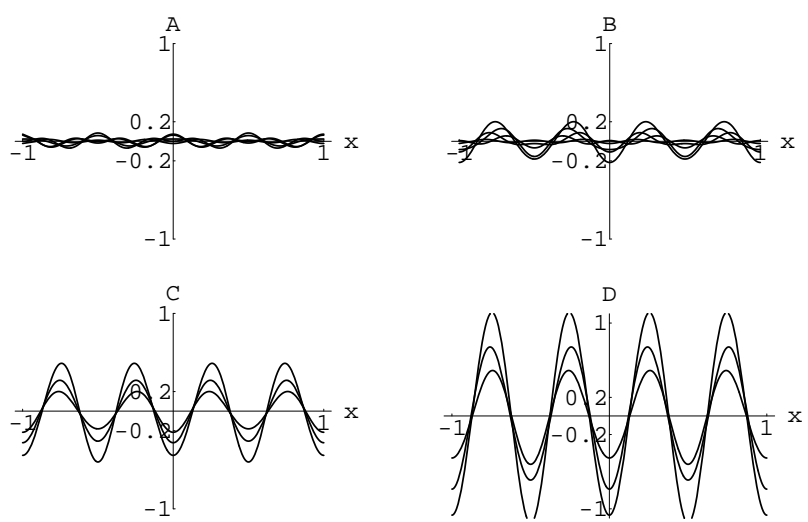

Figure 7. Projection at the scale $N=1$ of the term $v(x, t)$ describing the contribution of the level $N=1$. A: $0<t<0.8$, B: $0.8<t<1.2$, C: $1.2<t<1.4$, D: $1.4<t<1.6$.

where $u^{1}(x), u^{2}(x)$ are the basic solutions at the level $N=0$. The evolution of the initial profiles is such that the amplitude of the resulting wave is a combination of the basic wave at level $N=0$ with a wave at level $N=1$. The contribution of the level $N=1: v(x, t)=v^{1}(x, t)+v^{2}(x, t)$, is a periodic function with neglectable amplitude at initial time and $t<1$, but it becomes consistent thereafter (Fig. 7). 


\section{CONCLUSION}

The analysis of the wave propagation in a two phase composite material has been carried out by using harmonic wavelets. According to the multiresolution analysis, by increasing the order of the approximation more details are added to the investigation. In particular it has been shown that some additional oscillations are present during the evolution and this phenomenon, physically known, has been analytically detected using (suitable) wavelets.

\section{REFERENCES}

[1] N.M. Astafeva. Wavelet analysis: basic theory and examples of applications. Usp. Phys. Nauk, 166(11), 1145 - 1170, 1996.

[2] C. Cattani. The wavelets based technique in the dispersive wave propagation. International Applied Mechanics, 39(4), 132 - 140, 2003.

[3] C. Cattani. Haar wavelet based technique for sharp jumps classification. Mathematical Computer Modelling, 2004.

[4] C. Cattani. Haar wavelets based technique in evolution problems. Proc. Estonian Acad. of Sciences, Phys. Math., 53(1), 2004.

[5] C. Cattani and J. J. Rushchitsky. On the subharmonic resonance and the second harmonics of a plane wave in nonlinearly elastic bodies. International Applied Mechanics, 39(1), $109-115,2003$.

[6] V. Ciancio and C. Cattani. On the propagation of transverse acoustic waves in the form of harmonic wavelets in isotropic media. In: Grigorios Tsagas(Ed.), Proc. of the Conference on Applied Geometry-General Relativity and the Workshop of Global Analysis, Differential Geometry and Lie Algebras, BSG Proceedings 9, Bucharest, Romania, 249 $-262,2003$.

[7] I. Daubechies. Ten Lectures on wavelets. SIAM, Philadelphia, 1992.

[8] V.A. Geranin, L.D. Pysarenko and J.J. Rushchitsky. Theory of Wavelet analysis with elements of fractal analysis. VPF UkrINTEL, Kyiv, 2002. (in Ukrainian)

[9] B.P. Maslov, J.J. Rushchitsky and A.P. Kovalenko. Physical constants of the nonlinear microstructural theory of a two-phase mixture- calculated for a number of granular structural composite materials. International Applied Mechanics, 32(12), 80 - 89, 1996.

[10] S.V. Muniandy and I.M. Moroz. Galerkin modelling of the Burgers equation using harmonic wavelets. Phys.Lett. A, 235, $352-356,1997$.

[11] D.E. Newland. Harmonic wavelet analysis. Proc.R.Soc.Lond. A, 443, 203 - 222, 1993.

[12] J.J. Rushchitsky and S.I. Tsurpal. Waves in Materials with the Microstructure. Timoshenko Institute of Mechanics, Kyiv, 1997. (Ukrainian) 


\title{
Daugiasluoksnė bangos plitimo kompozicinèse medžiagose analizė
}

\author{
C. Cattani
}

Darbe nagrinejjamas Kleino-Gordono lygčių tiesinėje fazių mikrostruktūriniu medžiagu teorijoje daugiasluoksnio uždavinio sprendimas. Sprendiniui nustatyti naudojamasi bangelių šeima, turinčia harmoninių bangelių prigimtį. Jungties koeficientai tiksliai randami ir nusakomi diferencialinių lygčių rinkiniu. Bangos plitimas yra nagrinèjamas kaip bangelių skirtinguose sluoksniuose aproksimacijos superpozicija, priklausanti tiek nuo fizikinių parametrų, tiek nuo jungties koeficientų kiekviename sluoksnyje. Grubus priartejjimo lygmuo nagrinėja tik harmonines slinktis, kai, tuo tarpu, smulkios detalès, atsirandančios subtilesniuose lygmenyse, aorašo smulkias osciliacijas aplink harmoninę nulinio lygio aproksimaciją. 